\title{
Preventive Program for Optimal Performance in Elite Wheelchair Basketball Players
}

\author{
Javier Pérez-Tejero and Saleky García-Gómez* \\ Sanitas Foundation Chair for Inclusive Sport Studies, Faculty of Physical Activity and Sports Sciences, Universidad Politécnica de Madrid, Spain
} Submission: February 10, 2020; Published: February 25, 2020

*Corresponding author: Saleky García-Gómez, Sanitas Foundation Chair for Inclusive Sport Studies, Faculty of Physical Activity and Sports Sciences, Universidad Politécnica de Madrid, Martín Fierro, 7, 28040, Madrid, Spain

\begin{abstract}
Health intervention in adapted sport has been a critical issue in order to decrease musculoskeletal injuries. In this regard, shoulder injuries are a common problem among wheelchair basketball players (WB). Research in adapted sport injuries is increasing all over the years; however it is necessary to implement protocols to treat and prevent injuries in wheelchair sports. Shoulder home-based preventive program has demonstrated to be useful for maintaining shoulder health conditions of WB players throughout their sport training regimes when preparing for an international competition. This allows it to be useful complementary tool in combination with teams' technical strategy.

Keywords: Adapted sport; Paralympic sport; Wheelchair injuries; Shoulder biomechanics; prevention; Exercise

Abbreviations: SHEP: Shoulder Home-based Exercise Program; WB: Wheel chair Basketball
\end{abstract}

\section{Introduction}

In order to improve the performance of elite wheelchair basketball players, experts in sport and health science have suggested exercise programs to prevent and treat injuries. Studies suggest that exercise program is a useful tool as an element to prevent and to treat shoulder pain as a result of injuries [1,2]. Being biomechanical aspects, related to mechanics of the sport, the impairment type and level a standing point to develop a strategy. Practical guidelines and recommendations are published to the prevention and management of exercise in manual wheelchairs users; however, only a few evidence of general recommendations for wheelchair basketball athletes. In this regard, some researches $[3,4]$ show how exercise program could influence in SP in wheelchair population. On other hand, previous researches are developed in elite WB population including prevention of shoulder injury in collegiate WB payers $[5,6]$.

\section{Interventional Study}

An interventional study show that a shoulder home-based exercises program (SHEP) [7] appears to be useful tool for maintaining shoulder conditions of WB players throughout their sport training regimes when preparing for elite WB competitions, such as the Paralympic Games. In a group of WB players who received a 10 week SHEP, the changes in SP and ROM were not significantly different from the changes observed in the CG that did not receive the intervention. For both groups, no increase in neither SP nor shoulder injuries was observed, so the functionality and the health of the shoulder were preserved. However, in females WB players there were a significantly reduction of shoulder pain after 10 weeks of the SHEP intervention and an increase of the shoulder functionability.

\section{Discussion}

Preventive programs for optimal performance establish the incidence and severity of the problem, the etiology and mechanism of injury, implement the preventive measure and determine the effectiveness of the intervention. A preventive program for wheelchair basketball appears as a convenient tool to maintain the shoulder health condition during the training process working in line with teams' technical strategy, where players realize a high level of training [7], high impact loading and repeated actions that can develop injuries. In this regard, WB players require regular evaluations, also, multidisciplinary team need to be coordinated to implement and promote an adequate intervention, being necessary the synergy between clubs and 
institutions. Futher perspectives needed to develop technological innovations that include a protocol with aspects related to the musculoskeletal condition in wheelchair athletes. Also, is needed to determine the effectiveness of the SHEP in a larger sample and include prevention programs in the junior players' preparation.

\section{References}

1. Van Straaten MG, Cloud BA, Morrow MM, Ludewig PM, Zhao KD, et al. (2014) Effectiveness of home exercise on pain, function, and strength of manual wheelchair users with spinal cord injury: A high-dose shoulder program with telerehabilitation. Arch Phys Med Rehabil 95(10): 1810-1817.

2. Gauthier C, Brosseau R, Hicks AL, Gagnon DH, et al. (2018) Feasibility, Safety, and Preliminary Effectiveness of a Home-Based Self-Managed High-Intensity Interval Training Program Offered Long-Term Manual Wheelchair Users. Rehabil Res Pract 2018: 8209360
3. Akanksha Satyavanshi, Monalisa Pattnaik, Patitapaban Mohanty (2017) Comparison of two types of strengthening exercises in upper limbs for improvement of wheelchair propulsion in paraplegics. J Novel Physiother Rehabil 1: 27-33.

4. Mulroy S, Haubert LL, Eberly V, Conners S, Weiss W (2017) Effectiveness of two intervention programs to prevent shoulder pain after spinal cord injury. Arch Phys Med Rehabil 98(12): 174.

5. Akınoğlu B, Kocahan T (2017) Characteristics of upper extremity's muscle strength in Turkish national wheelchair basketball player's team. J Exerc Rehabil 13(1): 62-67.

6. Wilroy J, Hibberd E (2017) Evaluation of a shoulder injury prevention program in wheelchair basketball. J Sport Rehabil 27(6): 554-559.

7. García-Gómez S, Pérez-Tejero J, Hoozemans M, Barakat R (2019) Effect of a Home-based Exercise Program on Shoulder Pain and Range of Motion in Elite Wheelchair Basketball Players: A Non-Randomized Controlled Trial. Sports 7(8): 180.

\section{Your next submission with Juniper Publishers will reach you the below assets}

- Quality Editorial service

- Swift Peer Review

- Reprints availability

- E-prints Service

- Manuscript Podcast for convenient understanding

- Global attainment for your research

- Manuscript accessibility in different formats ( Pdf, E-pub, Full Text, Audio)

- Unceasing customer service

Track the below URL for one-step submission https://juniperpublishers.com/online-submission.php 